\title{
Studies on processing, particle formation, and immunogenicity of the HIV-1 gag gene product: a possible component of a HIV vaccine
}

\author{
R. Wagner ${ }^{1}$, H. FlieBbach ${ }^{1}$, G. Wanner ${ }^{2}$, M. Motz ${ }^{1, *}$, M. Niedrig ${ }^{3}$, Gabriele Deby ${ }^{1}$, \\ A. von Brunn ${ }^{1}$, and H. Wolf ${ }^{1}$ \\ ${ }^{1}$ Max von Pettenkofer Institute and ${ }^{2}$ Department of Botany, University of Munich, \\ Munich, \\ ${ }^{3}$ Behringwerke AG, Marburg, Federal Republic of Germany
}

Accepted April 13, 1992

Summary. Antigens in a particulate conformation were shown to be highly immunogenic in mammals. For this reason, the particle forming capacity of derivatives of the HIV-1 group specific core antigen p $55 \mathrm{gag}$ was assayed and compared dependent on various expression systems: recombinant bacteria, vaccinia- and baculoviruses were established encoding the entire core protein $\mathrm{p} 55$ either in its authentic sequence or lacking the myristylation consensus signal. Moreover, p $55 \mathrm{gag}$ was expressed in combination with the protease (p 55-PR) or with the entire polymerase ( $\mathrm{p} 55-\mathrm{pol}$ ), respectively. Budding of $100-160 \mathrm{~nm}$ p 55 core particles, resembling immature HIV-virions, was observed in the eucaryotic expression systems only. In comparison to the vaccinia virus driven expression of $\mathrm{p} 55$ in mammalian cells, considerably higher yields of particulate core antigen were obtained by infection of Spodoptera frugiperda (Sf9) insect cells with the recombinant Autographa californica nuclear polyhedrosis (AcMNPV) baculovirus. Mutation of the $\mathrm{NH}_{2}$-terminal myristylation signal sequence prevented budding of the immature core particles. Expression of the HIV p 55-PR gene construct by recombinant baculovirus resulted in complete processing of the $\mathrm{p} 55 \mathrm{gag}$ precursor molecule in this system. The introduction of an artificial frameshift near the natural frameshift site resulted in constitutive expression of the viral protease and complete processing of p 55, both in Escherichia coli and in vaccinia virus infected cells. Interestingly, significant processing of $\mathrm{p} 55$ resembling that of HIV infected $\mathrm{H} 9$ cells could also be achieved in the vaccinia system by fusing the entire pol gene to the gag gene. Moreover,

\footnotetext{
* Present adress: Mikrogen GmbH, Munich, Federal Republic of Germany.
} 
processing was not found to be dependent on amino-terminal myristylation of the gag procursor molecule, which is in contrast to observations with type $\mathrm{C}$ and type D retrovirus. However, complete processing of p 55 into p 24, p 17, p 9 and p 6 abolished particle formation. Purified immature HIV-virus like particles were highly immunogenic in rabbits, leading to a strong humoral immune response after immunization. Empty immature p 55 gag particles represent a noninfectious and attractive candidate for a basic vaccine component.

\section{Introduction}

The medical importance of HIV-1 and HIV-2 infections accelerated the detailed biochemical and immunological definition of structural and regulatory proteins of lentiviruses. Intensive work focused on the molecular process leading to the assembly of HIV-virions as one of the key mechanisms in the life cycle of HIV. Increasing attention has been paid to the group specific antigens of HIV-1. The HIV-1 gag open reading frame encodes a $55 \mathrm{kDa}$ polyprotein which is subsequently processed into the mature, nonglycosylated matrix protein p 17 (MA), the capsid protein $\mathrm{p} 24$ (CA); the nucleoprotein $\mathrm{p} 9$ (NP) and a link protein $\mathrm{p} 6$ (LI) $[25,31,41]$. Cleavage of the gag precursor to yield the mature capsid proteins is at least in part specified by the viral protease (PR) $[2,19,20,23]$. The viral protease is encoded by the $\mathrm{NH}_{2}$-terminal region of the pol open reading frame which contains precursor forms necessary for viral replication. The pol gene products are initially synthesized as a $160 \mathrm{kDa}$ gagpol fusion protein, which results from a $(-1)$ translational frameshift occurring at a relatively low frequency in the gagpol overlapping region [14]. This polyprotein precursor molecule may be autocatalytically processed into the $9 \mathrm{kDa}$ protease $(\mathrm{PR})$, the reverse transcriptase (RT), the integrase (IN) and mature core proteins. As for other retroviruses $[13,41]$ the $\mathrm{NH}_{2}$-termini of both, the $55 \mathrm{kDa}$ and the $160 \mathrm{kDa}$ precursor proteins are myristylated.

The exact role of the myristyl-moiety and the $\mathrm{NH}_{2}$-terminus of the capsid presursor molecule is not clear to date, although it has been identified at the amino-terminus of a number of retroviral gag products $[35,41]$. Myristylation of the gag precursor typically occurs cotranslationally [43] and is specified by the $\mathrm{NH}_{2}$-terminal glycine residue next to the methionine derived from the initiation codon [15]. Obviously, the myristic acid moiety at the amino terminus of $p 17$ is essential for the release of HIV virus particles [13]. Functions as membrane anchor [14] or signal for intracellular transport [33] have been suggested. As has been also shown in type C Moloney murine leukemia viruses (Mo-MuLV), myristylation of the HIV-1 p $55 \mathrm{gag}$ polyprotein precursor is essential for its membrane localization and assembly of capsid protein into discrete particles at the plasma membrane. Changes in the p 17 amino-terminal glycine of provirus clones abolish myristylation of the HIV-1 precursor proteins and prevent virus particle release from transfected cells. In contrast to Mo-MuLV and type D Mason-Pfitzer monkey virus (MPMV), processing of the p 55 capsid precursor is not inhibited in myristylation deficient variants of HIV-1 proviral 
clones [9]. Several groups investigated the role of $p 55$ in the assembly of virus particles when expressed in eucaryotic cells such as yeast [19] and mammalian cells using plasmid vectors [37] or recombinant vaccinia virus $[11,29,36]$. Budding of virus-like particles has recently been shown from a baculovirus vector in insect cells $[3,6]$.

Due to its group specificity and its particle forming capacity, the HIV core antigen is a promising candidate for vaccine development. As known from other systems such as hepatitis B virus, particulate antigens are highly immunogenic and possess intrinsic adjuvant properties [26]. High antibody titers to p55 during early stages of infection, the inhibiting activity of reactive monoclonal antibodies in vitro [30] and the significance of core proteins in the elimination of infected cells by cytolytic T-cells [28] support the role of p $55 \mathrm{gag}$ in future candidate vaccines. For this reason we conducted a detailed comparative analysis of the particle forming capacity of the HIV-1 core antigen. Identical DNAconstructs containing the entire gag in its natural configuration were established and altered (i) into a myristylation deficient form, (ii) combined with the protease, (iii) either in its natural configuration or in frame to $\mathrm{p} 17 / \mathrm{p} 24$ and (iv) fused to the entire pol coding sequence. The different polypeptides were expressed in $E$. coli as well as by recombinant vaccinia- and baculoviruses in mammalian and insect cells, respectively. The experiments reported here compare the influence of myristylation and protease activity on HIV-1 core expression and particle assembly in various expression systems in order to identify optimal conditions for the formation of recombinant core particles. Evidence is presented for the induction of a core specific humoral immune response after immunisation of rabbits with purified core particles.

\section{Materials and methods}

\section{Plasmid DNA}

A DNA clone containing HIV-1 sequences, $\mathrm{pBH} 102$, was kindly provided by Prof. Gallo, NIH, Bethesda, MD, U.S.A. The baculovirus expression vector pVL 941 was provided by Dr. Summers, Texas A\&M University, College Station, TX, U.S.A. All reported were propagated in Eschericha coli strain JM 109.

\section{Cells}

Green monkey kidney CV-1 cells, SW 480 colon carcinoma cells and B 143 cells were grown in Eagles minimal essential medium (MEM) containing 5\% fetal calf serum. Spodoptera frugiperda (Sf9) insect cells were propagated in TC 100 medium (GIBCO/BRL, Federal Republic of Germany) supplemented with $10 \%$ fetal calf serum.

\section{Sera and monoclonal antibodies}

Production and mapping of p 24 specific mouse monoclonal antibody 16/4/2 used for immunoblotting was previously described by Wolf et al. [26]. A p 17 specific mouse monoclonal antibody was kindly provided by Prof. Chandra, University of Frankfurt, Federal Republic of Germany. A rabbit serum directed against the HIV-1 protease was obtained 
by Prof. von der Helm, Max von Pettenkofer Institute, Munich, Federal Republic of Germany.

\section{Construction of recombinant plasmids}

In order to obtain precise $\mathrm{NH}_{2}$-termini of the capsid precursor we inserted a $62 \mathrm{bp}$ oligonucleotide, GATCCATGG GTGCGAGAGC GTCAGTATTA AGCGGGGGAG AATTAGATCG ATGTCGACCT GCA, encoding the $15 \mathrm{NH}_{2}$-terminal amino acids of $\mathrm{p} 55 \mathrm{gag}$ into the $\mathrm{Bam} \mathrm{HI} / \mathrm{Hind}$ III site of the pUC 8 vector. The restriction sites $\mathrm{Cla}$ I and $\mathrm{Sal} I$ in the $3^{\prime}$ position within the oligonucleotide were used to complete the gag reading frame by insertion of a $1694 \mathrm{bp} \mathrm{Cla} /$ /Hinc II fragment resulting in plasmid pUC8 555 .

For expression of the myristylation deficient capsid precursor, we replaced the $47 \mathrm{bp}$ Bam HI/Cla I fragment encoding the amino-terminal part of $\mathrm{p} 17$ by a corresponding DNA fragment,

GATTCGTGCA CGCCATGGCT GCGAGAGCGT CAGTATTAAG CGGGGGAGAA TTAGAT.

A $\mathrm{G}$ to $\mathrm{C}$ transition alters the $\mathrm{NH}_{2}$-terminal glycine residue into an alanine thereby destroying the myristylation signal sequence ( $\mathrm{pUC} 8 \mathrm{p} 55 \mathrm{M}^{-}$). The correct sequence was verified by double strand sequencing using a $\mathrm{T} 4$ polymerase sequencing kit (BRL).

To express p $55 \mathrm{gag}$ with the exact protease polypeptide (PR) without additional carboxy-terminal polymerase ( $P O l$ ) sequences we inserted a synthetic polylinker sequence,

AATTCGGATT CGTTGACCTG CAGTAATTAA TTAGATCTCG AGCCCGCCTA ATGAGCGGGC TTTTTTGAGC TCA

into the Eco RI/Hind III restriction sites of pUC 8. This linker fragment contained stop codons in all reading frames (italics) and a procaryotic rho independent transcription termination signal (pUC 8 stop) to increase the production of recombinant proteins in $E$.

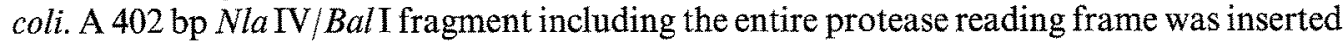
into the Hinc II site of pUC 8 stop to yield pUC 8 PR stop. For insertion of the p $55 \mathrm{gag}$ coding sequence, we fused the $\mathrm{pUC} 8 \mathrm{p} 55$ derived $B a m \mathrm{HI} / B c l$ I fragment with the $B a m \mathrm{HI} /$ $B c l$ I fragment of pUC8 PR stop to create pUC8 p55 PR.

To combine the gag and the protease gene in the same open reading frame, the $B g l \mathrm{II}$ restriction site of pUC8 p55 PR was opened, filled enzymatically using the Klenow fragment and religated, thereby creating an additional $\mathrm{Cla}$ I site. The resulting plasmid was called pUC8 p55 PR-FS. The enforced frameshift replaced the carboxy terminal 63 amino acids of $\mathrm{p} 15$ by the HIV-1 protease. The regular ribosomal frameshift site is located $6 \mathrm{bp}$ upstream of the generated Cla I site.

To align both the myristylation competent and incompetent forms of the gag gene with the entire pol gene, we replaced the $437 \mathrm{bp} \mathrm{BglII/SalI}$ fragment of pUC8 p55 and of pUC8 $55 \mathrm{M}^{-}$by a 3727 bp Bgl II/Sal I fragment including $\mathrm{p} 15$ and the complete pol gene to create pUC8 p55 Pol and pUC8 p55 $\mathrm{M}^{-}$Pol.

For production of the recombinant proteins and following characterization in E.coli, we subcloned the coding sequences into a $\mathrm{Nco}$ I/SalI digested pTRC 99 ATG-vector to avoid expression of disturbing $\mathrm{LacZ}$ derived $\mathrm{NH}_{2}$-terminal sequences.

To establish recombinant vaccinia viruses, the pUC derived gag-gene constructs were subcloned into the $B g l \mathrm{II} / S a l \mathrm{I}$ digested $\mathrm{pAvB}$ vaccinia transfer vector [27] to create pAvBp 55, pAvB 55 $\mathrm{M}^{-}$, pAvBp 55 PR, pAvBp 55 Pol, pAvBp $55 \mathrm{M}^{-}$Pol and pAvBPRFS. For expression by recombinant baculovirus, we subcloned two relevant inserts, encoding p 55 and for comparison p55 PR (Fig. 1), into the Bam HI site of the transfer vector pVL 941 [37]. The basic gene constructs and the expression of the polypeptides in the respective expression systems are summarized in Fig. 1. 

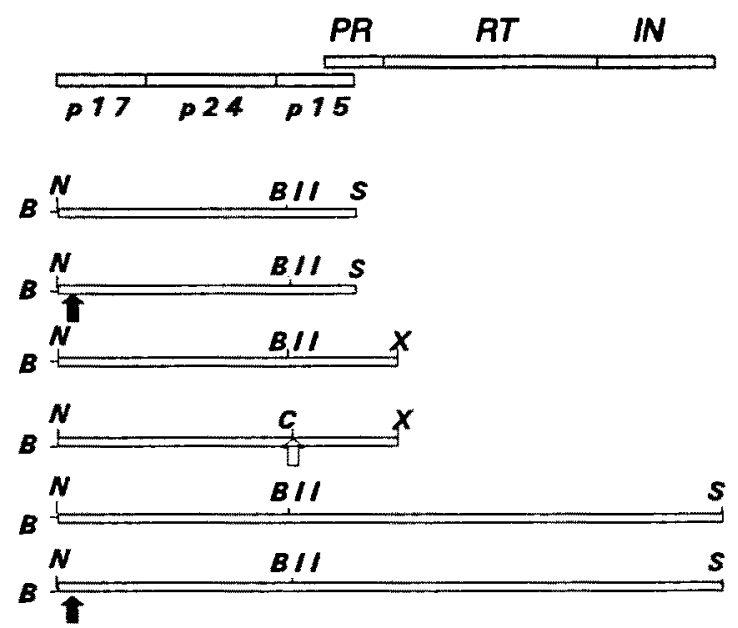

\begin{tabular}{|c|c|c|}
\hline $\begin{array}{l}\text { PTRC } \\
\text { E. coli }\end{array}$ & $\begin{array}{l}\text { pAvB } \\
\text { Vaccinia (v) }\end{array}$ & $\begin{array}{l}\text { pVL941 } \\
\text { Baculo (b) }\end{array}$ \\
\hline p 55 & $255^{\circ}$ & $p 55^{\infty}$ \\
\hline$p 55 M^{-}$ & $p 55 M^{-}$ & N.D. \\
\hline P55PR & P55PR & P55PR \\
\hline P55PR-FS & P55PR-FS & N.D. \\
\hline P55Pol & p55Pol & N.D. \\
\hline P55M-Pof & p55M-Pol & N.D. \\
\hline
\end{tabular}

Fig. 1. Schematic reconstruction of the p 55 and Pol coding sequence. Genomic regions, which were included into the basic constructs are depicted as open bars. Abbreviations of the plasmids and recombinant viruses, described in the text are shown on the right. Restriction sites essential for subcloning are indicated (B Bam HI; N Nco I; BII BglII; S Sal I; $\mathrm{X}$ Xho I; $\mathrm{C} \mathrm{Cla} \mathrm{I).} \mathrm{Mutations} \mathrm{introduced} \mathrm{to} \mathrm{change} \mathrm{functional} \mathrm{properties} \mathrm{of} \mathrm{the} \mathrm{depicted}$ reading frames are indicated by an open arrow ( -1 frame shift induced by the Klenow fragment at the $B g l \mathrm{II}$ restriction site, resulting in a new $\mathrm{Cla}$ I site) and solid arrows (myristylation signal, Gly-Ala). Biological properties of the polyproteins such as processing of precursor molecules $(\boldsymbol{\Delta})$ and particle forming capacity $(\boldsymbol{O})$ are indicated

\section{Construction of recombinant vaccinia viruses}

Transfer of the HIV-1 genes from the recombinant plasmids pAvBp 55, pAvBp 55 $\mathrm{M}^{-}$, pAvBp 55PR, pAvBp 55PR-FS, pAvBp 55 Pol and pAvBp 55 $\mathrm{M}^{-}$Pol into vaccinia virus Tien Tan (VTT) was achieved by a standard homologous recombination method using CV1 cells [24]. The recombinant vaccinia viruses were designated as v-p $55, v-p 55 \mathrm{M}^{-}, \mathrm{v}-$ p 55 PR, v-p 55 PR-FS, v-p 55 Pol and v-p $55 \mathrm{M}^{-}$Pol, respectively.

\section{Construction of recombinant baculovirus}

Sf 9 cells were cotransfected with mixtures of infectious Autographa califonica nuclear polyhedrosis virus (AcMNPV) DNA and $\mathrm{CsCl}$ purified [34] transfer vector DNA as described by Smith et al. Resultant progeny baculovirus was used to produce plaques in Sf 9 cell monolayers. Plaques lacking polyhedrin structures were selected, purified by further plaque assays and used to produce virus stocks.

\section{Analysis of recombinant polypeptides}

IPTG induced recombinant bacteria were harvested and resuspended in lysis buffer as described by Sambrook et al. [34]. CV-1 cells were infected with wild type vTT or recombinant vaccinia virus at $10-20 \mathrm{pfu}$ per cell and incubated at $37^{\circ} \mathrm{C}$ for $24 \mathrm{~h}$ in serum free MEM. Infected cells were harvested and resuspended in boiling mix. Monolayers of Sf 9 cells were infected with wild type AcMNPV or recombinant baculovirus at a multiplicity of 5-10 pfu/cell and incubated at $28^{\circ} \mathrm{C}$ for $1-5$ days. Cells were harvested and suspended in the lysis buffer. Supernatant was, without concentration of the recombinant protein, directly mixed with lysis buffer. Protein extracts were boiled for $5 \mathrm{~min}$ at $100^{\circ} \mathrm{C}$ and analyzed 
by SDS-PAGE and Western blotting [21]. Immunological detection was performed using monoclonal antibodies directed to p 24 [44], p 17 and a pool of AIDS patient sera.

\section{Electron microscopy}

Infected SW 480 and Sf 9 cells were harvested with a cell scraper, washed with phosphate buffered saline (PBS) and then fixed for $2 \mathrm{~h}$ with $2.5 \%$ glutaraldehyde in PBS. Cells were washed with PBS and postfixed for $1 \mathrm{~h}$ with osmium tetroxide in PBS. After washing in PBS and in distilled water, fixed cells were stained with $1 \%$ uranyl acetate in $20 \%$ acetone for $30 \mathrm{~min}$. Following dehydration in a graded series of acetone cells were embedded in Spurr's low-viscosity resin. Sections of 25 to $75 \mathrm{~nm}$ thickness were cut with a diamond knife and mounted on uncoated copper grids. The sections were poststained with $100 \mathrm{mmol} \mathrm{Pb}-$ citrate $\mathrm{pH}$ 12.6. All pictures were taken with Siemens Elmiskop 101 electron microscope. The magnification was calibrated with a cross line grating replica.

\section{Gradient sedimentation analysis}

Supernatants of Sf 9 cells infected with the recombinant baculoviruses b-p55 and b-p55 PR were collected 5 days p.i. from synthetic medium lacking FCS. Enrichment of core particles from precleared culture supernatant $(3300 \times \mathbf{g})$ was achieved by a Ultrasette-Filtron filter membrane (Satorius, Federal Republic of Germany) after the protocol of the manufacturers. $2 \mathrm{ml}$ aliquots of the concentrated material was layered onto a $12 \mathrm{ml} \mathrm{10-60 \%} \mathrm{sucrose} \mathrm{gradient}$ in $10 \mathrm{mM}$ phosphate buffer $\mathrm{pH} 7.5$ containing $0.15 \mathrm{M} \mathrm{NaCl}$ and run at $20,000 \mathrm{rpm}$ for $2 \mathrm{~h}$ in a Kontron TFT 41.14 rotor. Fractions $(0.7 \mathrm{ml})$ were collected and directly assayed by conventional Western blot analysis. The yield of recombinant gag particles was determined using a commercial p 24/p 55 specific antigen capture assay (Abbot).

\section{Reverse transcriptase assay}

Supernatants of uninfected SW 480 cells and cells infected by the recombinant vaccinia viruses v-p55, v-p55 $\mathrm{M}^{-1}$ Pol and v-p55 Pol (10 pfu/cell) were collected 2 days p.i. and precleared in a Kontron A 8.24 rotor for $15 \mathrm{~min}$ with $8000 \mathrm{rpm}$. The supernatant was layered onto a $2 \mathrm{ml} 37 \%$ sucrose cushion and ultracentrifuged at $5{ }^{\circ} \mathrm{C}$ for $2 \mathrm{~h}$ at $20,000 \mathrm{rpm}$ in a Kontron TFT 41.14 rotor. The supernatant was discarded and the pellet was assayed for RT activity in a reverse transcriptase test using poly $\mathrm{rA}: \mathrm{dT}$ and $\mathrm{Mg}^{++}$as described previously [10].

\section{Results}

\section{Basic constructs and concepts}

In order to conduct a detailed comparative analysis of the $\mathrm{p} 55$ particle forming capacity in different eucaryotic expression systems, we established a series of gag-gene constructs in the pUC vector system. In addition to the authentic p 55 gag gene (pUC8 p55), a mutant form of the gag precursor lacking the $\mathrm{NH}_{2}$ terminal myristylation signal sequence was constructed altering the glycine residue at position 2 of the amino acid sequence to alanine (gly to ala, pUC8 $\mathrm{p} 55 \mathrm{M}^{-}$). The effect of proteolytic processing on gag expression and particle formation was investigated by adding the protease (PR) coding sequence to the gag gene (i) in its natural configuration (pUC8 p55 PR) and (ii) in frame to p 55 (pUC8 p55 PR-FS). Finally, we added the entire pol gene to the " $\mathrm{p} 55$ " and "p55 $\mathrm{M}^{-}$" gene-constructs to reveal the proteolytic capacity of the HIV- 
1 protease in the complete $160 \mathrm{kDa}$ gagpol polyprotein and to investigate the effect of myristylation on the processing of the precursor molecules. Using identical gag-gene constructs the level of HIV-core expression, proteolytic events and efficiency of particle formation could be determined and directly compared in different vector systems. Basic constructs and results described in the results are summarized in Fig. 1.

\section{Expression and biochemical analysis of $p 55$ and $p 55$-derived polypeptides in E. coli}

After subcloning of the gag-gene constructs into the ATG-vector pTRC99, recombinant proteins were expressed in E. coli (Fig. 1). Immunoblot analysis using different $\mathrm{p} 24$ and $\mathrm{p} 17$ specific monoclonal antibodies revealed that all bacterial clones except pTRC p55 PR-FS expressed the authentic p $55 \mathrm{kDa}$ gag precursor. Significant, but not complete processing was observed in lysates of p55 PR-, p55 Pol- and p55 $\mathrm{M}^{-}$Pol-recombinant bacteria (data not shown). Reverse transcriptase activity was measured in both bacterial clones, containing the entire polymerase gene ( $\left.555 \mathrm{Pol} ; \mathrm{p} 55 \mathrm{M}^{-} \mathrm{Pol}\right)$.

In contrast, complete processing of the $65 \mathrm{kDa}$ p55 PR precursor was achieved expressing the PR-gene in frame with the gag gene (pTRCp55 PRFS). The p 24/25 cleavage products were clearly visible in a SDS-PAGE stained with coomassie brilliant blue and could easily be detected by conventional Western blot analysis using p 24 specific monoclonal antibodies. Further detection of $\mathrm{p} 17$ and the protease $(9 \mathrm{kDa})$ by a monoclonal antibody directed to p 17 and a monospecific peptide serum directed to protease sequences confirmed the complete processing (data not shown).

Alteration of the myristylation signal sequence did not affect $\mathrm{p} 55$ expression in E. coli. Neither sucrose gradient sedimentation analysis performed with culture supernatants of recombinant bacteria or cell extracts, nor electron microscopy analysis performed with recombinant bacteria gave any hint on HIVcore particle formation in E.coli (data not shown).

\section{Expression and biochemical analysis of $p 55$ and related constructs by recombinant vaccinia virus}

Expression of the described constructs in CV-1 cells by recombinant vaccinia viruses was a fast approach to evaluate parameters involved in processing and core particle assembly (Fig. 1). The recombinant vaccinia viruses (v-p55, vp55 $\mathrm{M}^{-}$, v-p55 PR, v-p55 PRFS, v-p55 Pol and v-p55 $\mathrm{M}^{-}$Pol) correspond exactly to the bacterial expression clones mentioned earlier. As shown by Western blot analysis (Fig. $2 \mathrm{~A}$ ), infection of CV-1 cells with v-p55, v-p55 $\mathrm{M}^{-}$and vp55 PR resulted in the expression of a $55 \mathrm{kDa}$ and, to a smaller extent, of a $41 \mathrm{kDa}$ protein. Addition of the exact HIV-1 protease coding sequence (vp55PR) was not sufficient for detectable processing of $\mathrm{p} 55 \mathrm{gag}$ in $\mathrm{CV}-1$ cells (Fig. $2 \mathrm{~A}$, lanes 5 and 12). The v-p55 PR derived $41 \mathrm{kDa}$ protein was clearly 


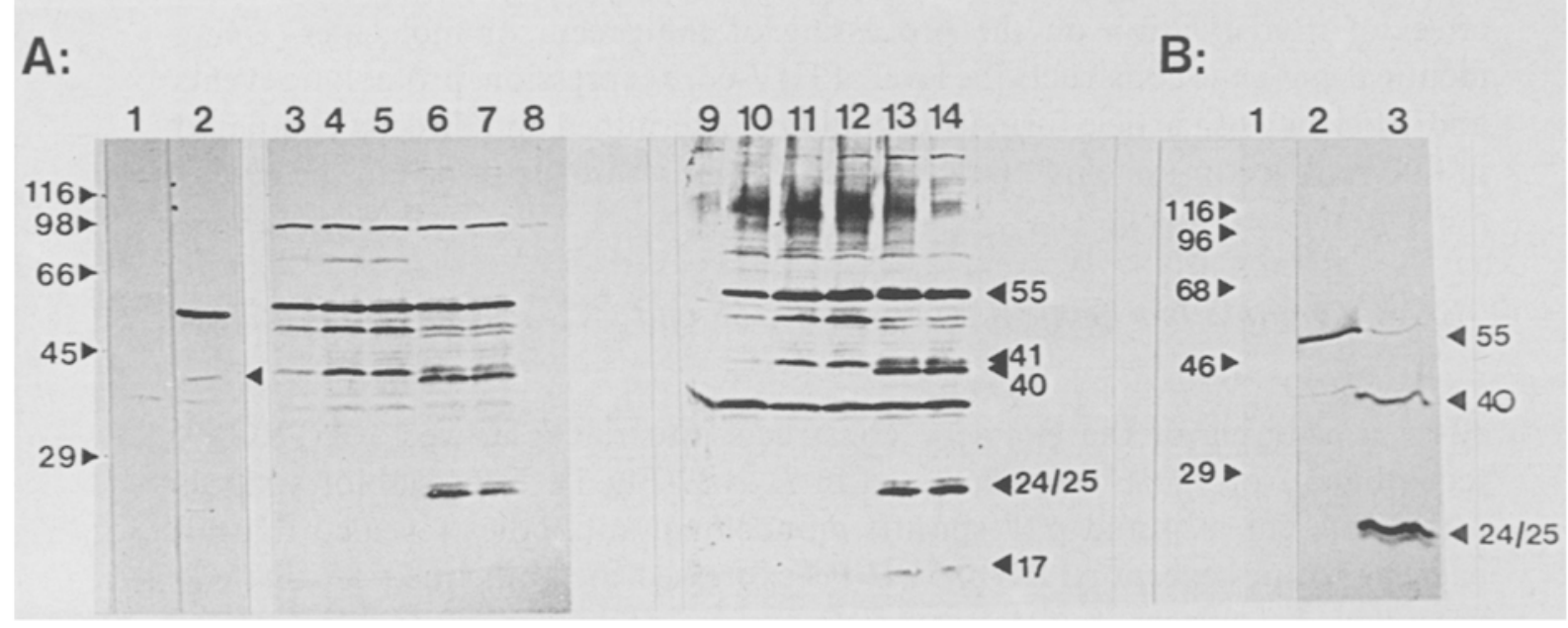

Fig. 2. A Pattern of proteins synthesized in CV-1 cells $\left(2 \times 10^{5}\right)$ after infection with different recombinant vaccinia viruses $(10 \mathrm{pfu} / \mathrm{cell})$. Recombinant polypeptides were specifically detected by Western blot analysis using murine monoclonal antibodies directed to p 17 ( 1 and 2), p $24(3-8)$ and by an AIDS patient serum pool (9-14). For negative control, CV1 cells were infected by vTT wild type vaccinia virus $(1,8$, and 9$)$. To compare the influence of myristylation and proteolytic processing on p 55 expression, cells were infected by v-p55 ( 3 and 10$), \mathrm{v}-\mathrm{p} 55 \mathrm{M}^{-}$(4 and 11$), \mathrm{v}$-p55 PR (2, 5, and 12), v-p55 Pol ( 6 and 13) and by vp55 $\mathrm{M}^{-} \mathrm{Pol}$ (7 and 14). B Complete processing in the vaccinia systems is shown in CV-1 cells infected with v-p55PR-FS (3) as compared to CV-1 cells infected with v-p55 (2) and wild type vaccinia virus vTT. Molecular weight markers are indicated $(\mathrm{kDa})$

recognized by a p 17 specific monoclonal antibody (Fig. $2 \mathrm{~A}$, lane 2). For this reason, the production of $\mathrm{p} 41$ was, at least partially, rather due to a suggested premature translational stop signal near the COOH-terminal part of the $\mathrm{p} 24$ coding sequence [9] than to HIV-mediated proteolytic events. Kinetical studies, following the infection over a period of $48 \mathrm{~h}$ did not show any specific, protease mediated processing, although the PR coding sequence was verified by DNA sequencing. In contrast to some previous reports $[4,36]$, we found significant processing when the entire pol reading frame was added to the gag gene. Unprocessed p 55 gag, p 24/25 and different gag-processing intermediates with an estimated molecular weight of $40-41 \mathrm{kDa}$ could now easily be detected in cell lysates (Fig. 2 A, lanes 6 and 7). Using a pool of sera from AIDS patients, $p 17$ could be shown in addition to the polypeptides mentioned earlier (Fig. $2 \mathrm{~A}$, lanes 13 and 14). As clearly demonstrated by analyzing extracts of v-p55 $\mathrm{M}^{-}$Pol infected CV-1 cells, processing was not dependent on previous myristylation of the gag precursor molecule. For comparison expression of p55 PR-FS resulted in an almost efficient processing of the core precursor in the vaccinia expression system (Fig. 2 B).

Sedimentation studies performed with culture supernatants and following Western blot analysis of the precipitated antigens gave identical results as 
described for the cellular extracts in the case of v-p55-, v-p55 PR and v-p55 Pol infected cells. No antigen was detectable in culture supernatants of cells infected with the myristylation deficient gag-constructs (v-p55 $\left.\mathrm{M}^{-}, \mathrm{v}-\mathrm{p} 55 \mathrm{M}^{-} \mathrm{Pol}\right)$ and with v-p55 PR-FS (data not shown). 2 days following infection with recombinant vaccinia viruses supernatants of SW 480 cells were analyzed for reverse transcriptase (RT) activity as described in Materials and methods. RT activity could be precipitated only from the culture supernatant of v-p55 Pol infected cells, not from supernatants of cells infected with the analogous myristylation deficient form (v-p55 M- Pol) (Fig. 3). These results gave first evidence ( $i$ ) for the release of particulate aggregates, that (ii) need $\mathrm{NH}_{2}$-terminal myristylation for the budding from the infected cells into the culture supernatant.

\section{Requirements for budding of immature particles from mammalian cells infected by recombinant vaccinia virus}

Budding of $\mathrm{p} 55$ core particles $(100-160 \mathrm{~nm}$ in diameter) from the plasma membrane and release into the culture medium was detected by electron microscopy after infection of SW 480 cells with v-p55, v-p55 PR and v-p55 Pol (Figs. 1 and 4). The lack of myristylation (v-p55 $\mathrm{M}^{-}, \mathrm{v}-\mathrm{p} 55 \mathrm{M}^{-}$Pol) at the $\mathrm{NH}_{2}$-termini apparently prevented targeting of the precursor polypeptides to the plasma membrane, confirming that myristylation of the polyprotein precursor is essential for its membrane localization and consecutive particle formation. Assembly was also abolished when the HIV-protease was expressed in an artificial construct in frame with p 55 (v-p55 PR-FS; data not shown). Analysing v-p55 Pol infected cells morphologically, we clearly detected p 55 particle formation and budding of recombinant particles into the culture supernatant. However, using the conventional vaccinia expression system, the yield of recombinant immature core particles was not sufficient for preparative scale fermentation.

The shape of p 55 gag particles produced by v-p55 and v-p55 Pol infected SW 480 cells is spherical, ovoidal or ellipsoid. The budding particles strongly resemble immature virus-like particles released from HIV-1 infected cell cultures $[5,16]$. There was no difference in a number of ultrathin sections detectable between v-p55 and v-p55 Pol derived core particles. Although we clearly found processing of the gag precursor in v-p55 Pol infected cells, we could neither find maturation of immature virus-like particles nor condensation of $\mathrm{p} 24$ to an

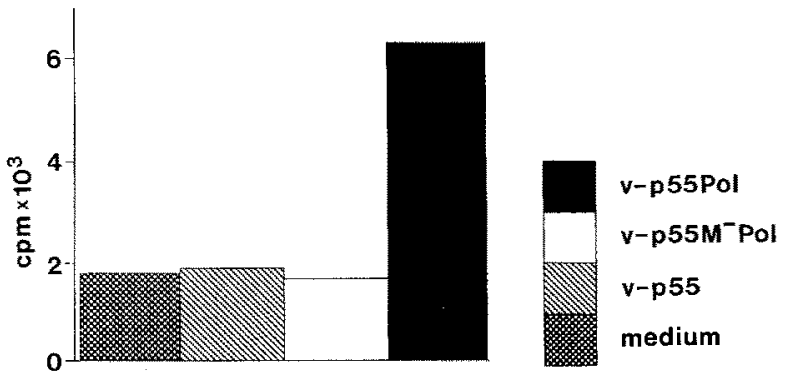

Fig. 3. Reverse transcriptase activity profile of supernatants from uninfected SW 480 cells and from SW 480 cells infected with the recombinant vaccinia viruses v-p55, $\mathrm{v}-\mathrm{p} 55 \mathrm{M}^{-}$Pol and v-p55 Pol 
electron dense conical capsid known from mature HIV virions. The diameters of the budding structures show variations from 100 to $160 \mathrm{~nm}$, whereas a mean diameter of $130 \mathrm{~nm}$ is most frequently observed. Vaccinia virus particles were larger $(290 \times 195 \mathrm{~nm})$ and could be easily distinguished from p55 gag particles (Fig. 4 B). Plasma membranes with a thickness of 6-7nm (Fig. 4A) formed spherical vesicles, the cytoplasmic site was coated by an electron-dense layer
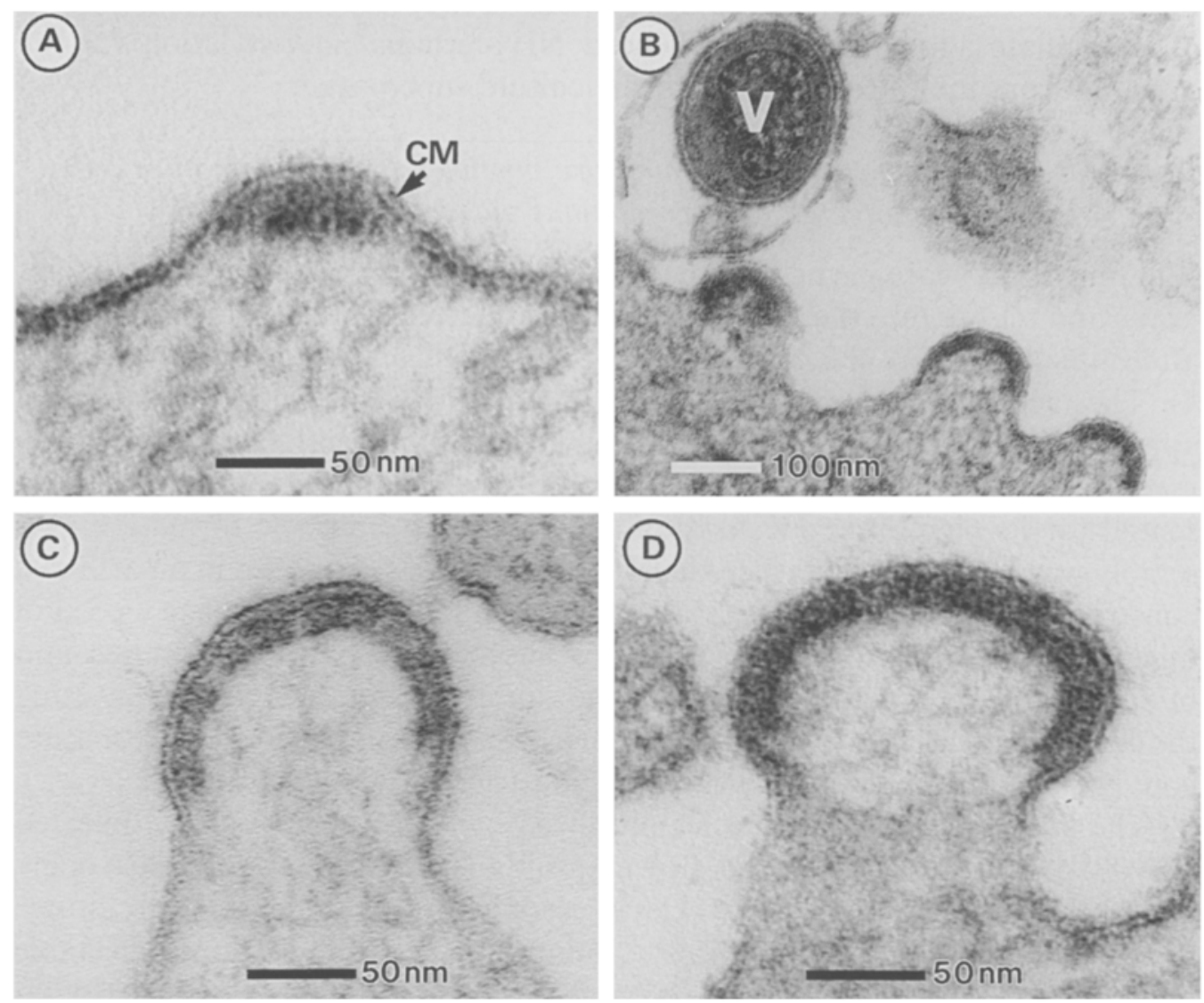

(E)

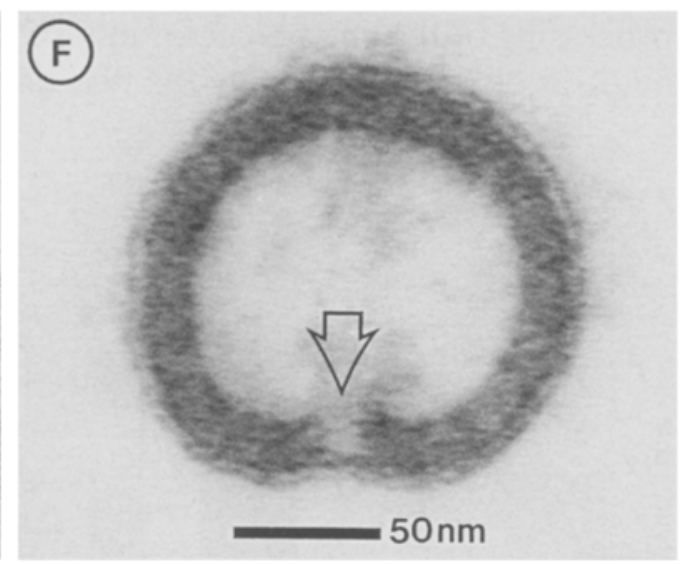


with a thickness of $14-17 \mathrm{~nm}$. Occasionally, this layer exhibited an additional, more electron dense border line (Fig. $4 \mathrm{E}$ ). The electron dense " $15 \mathrm{~nm}$ " layer was typically interrupted at the site of budding (Fig. 4E and F). Essentially, all p55 gag particles produced in the vaccinia system showed an electron-translucent lumen which exhibited by far less granular components that the cytoplasm. The content of fibrous material was similar to that of the cytoplasm.

\section{Expression and biochemical analysis of gag and related constructs in the baculovirus expression system}

To increase the yields of recombinant gag-particles and to analyze adverse effects of HIV protease mediated processing on particle formation, two of the basic constructs, pVL p55 and pVL p55PR, were expressed by a recombinant baculovirus in insect cells. Massive production of recombinant $\mathrm{p} 55$ was achieved by infection of Sf9 cells with b-p55 recombinant baculovirus (Fig. 5). It is noteworthy that unprocessed capsid precursor could be easily detected on immunoblots analyzing infected cells and in culture supernatants harvested 5 days p.i. without prior concentration. In parallel to high expression, proteolytic digestion of the capsid precursor by cellular or AcMNPV specific proteases could be observed in cellular extracts. In contrast to the vaccinia expression system (v-p55 PR; Fig. 2 A, B), addition of the HIV-1 protease gene (b-p55 PR) resulted in complete processing of the $\mathrm{p} 55$ precursor molecule in the baculovirus vector system.

\section{Budding of immature p55 gag particles following expression of the capsid precursor by recombinant baculovirus}

For analysis of the p 55 particle forming capacity, Sf 9 insect cells were infected with b-p55 and, for comparison, with b-p55PR. Infected cells were examined by electron microscopy (Fig. 6).

Fig. 4. Ultrathin sections of SW 480 cells infected by v-p 55 and v-p55 Pol recombinant vaccinia virus illustrating the typical budding mechanism. p55 gag precursor molecules accumulate, directed by amino-terminal myristylation, at the cytoplasmic site of the plasma membrane $(C M)$ forming electron dense hot spots (A). Proceeding aggregation of the capsid precursor forces the plasma membrane to form first hemispheral structures (B and $\mathbf{C}$ ), followed up by more spherical vesicular particles (D). Dissection of the immature p55 gag particles is managed by fusion of the plasma membrane. Appropriate section identifies the site of budding (open arrow), which is characterized by a local absence of the precursor molecule at the inner plasma membrane $(\mathbf{E}$ and $\mathbf{F})$. The architecture and the budding mechanism of both, v-p55 (C and E) and v-p55 Pol (D and F) seems to be identical. An internal osmiophilic borderline (E, small arrow) can be visualized in very thin sections $(35 \mathrm{~nm})$ as compared to $60 \mathrm{~nm}$ sections (F). B Due to its size and shape $(290 \times 195 \mathrm{~nm})$, recombinant vaccinia virus $(V)$ can be easily distinguished from the typical lentivirus-like budding core particles 


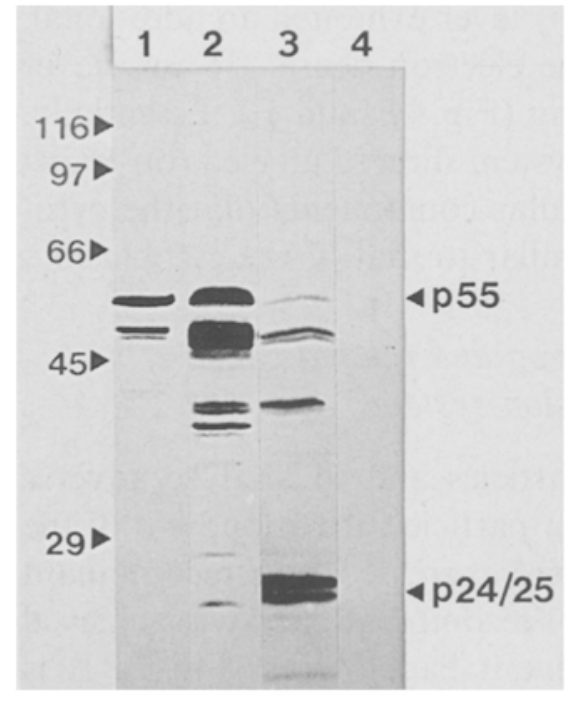

Fig. 5. Western blot analysis showing recombinant proteins expressed in Sf 9 cells $\left(6 \times 10^{4}\right)$ infected with recombinant baculovirus ( $5 \mathrm{pfu} / \mathrm{cell}$ ). Recombinant proteins were detected by the $\mathrm{p} 24$ specific monoclonal antibody [41]. I Supernatant $(10 \mu 1)$ of b-p55 infected Sf 9 cells 5 days p.i., 2-4 extracts of $S f 9$ cells harvested 5 days after infection with b-p55 (2), b-p55 PR (3) and with AcMNPV wild type baculovirus (4). Molecular weight markers are indicated $(\mathrm{kDa})$

B-p55 infected cells showed multiple lentivirus-like budding of particles with $100-160 \mathrm{~nm}$ in diameter strongly resembling those budding from v-p55 and vp55 Pol infected cells at the cell membrane surface (Fig. 4). These structures were not detected in Sf 9 cells infected by b-p55 PR and with wild type AcMNPV (data not shown). Assembly of the budding structures occurs at the cytoplasmic site of the plasma membrane. No particles or particulate structures were detected intracellularly. Production of the budding particles was abundant, leading to the release of single particles (Fig. 6A) and to oligomeric aggregation $(\mathrm{n}=2$ 4; Fig. 6 B) caused by incompletely dissociated complexes of budding structures or by monomeric particles fused immediately following the budding event. The structures dissociating from the cell membrane differed slightly in size and shape.

Immature particles, produced in Sf 9 cells showed an electron translucent center, which was covered by a dark, electron-dense ring and an outer 14-17 nm medium grey regular shell. The b-p55 derived particulate structures were surrounded by a $6-7 \mathrm{~nm}$ plasma membrane derived from the infected cell. Within the lumen of $555 \mathrm{gag}$ particles formed by the baculovirus system, electron-dense granules with diameters of about $15-20 \mathrm{~nm}$ were observed (Fig. 6). These extracellular p55 gag particles were similar to structures previously described as immature HIV-1 virions $[5,16]$. Ultrathin section electron microscopy performed with b-p55 PR infected cells revealed a dramatic decrease in $\mathrm{p} 55$ particle formation, possibly due to the observed complete intracellular processing of the gag-precursor (Fig. 5), thus confirming that complete intracellular processing prevents core particle formation.

In order to confirm p 55 particle formation and shedding of the particulate structures into the culture medium, we performed sucrose gradient sedimentation analyzing the culture supernatant of Sf 9 cells harvested 1-5 days after infection with b-p55. Fractions collected from the gradient were analyzed by immunoblotting followed by densitometric scanning. Highest yields of budding 

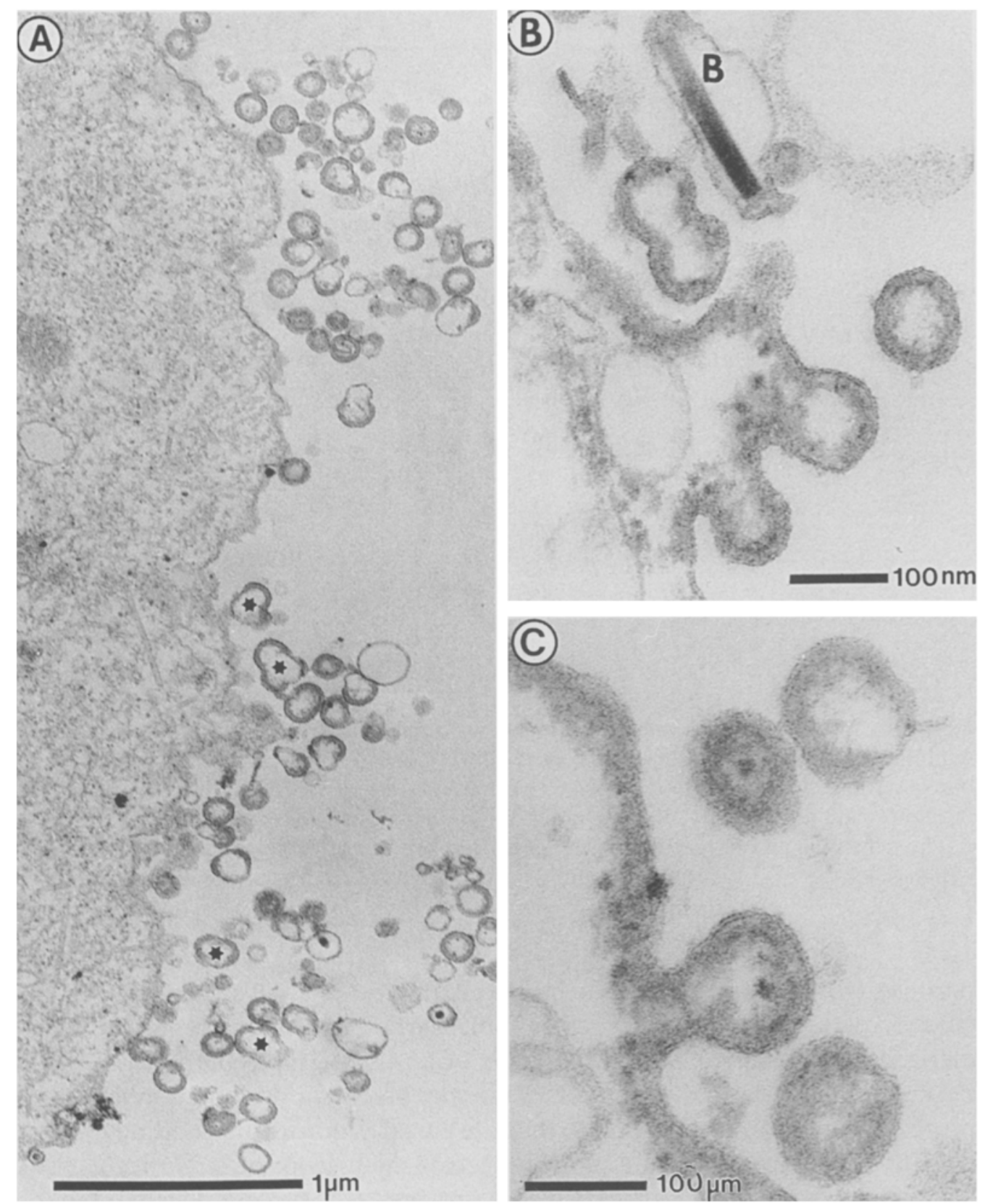

Fig. 6. Ultrathin section of Sf 9 cells infected with a b-p 55 recombinant baculovirus showing multiple budding of immature lentivirus like particles (A). The proposed mechanism of budding (B and $\mathbf{C}$ ) is analogous to that observed at the plasma membrane of SW 480 cells infected by the corresponding recombinant vaccinia virus (v-p55, Fig. 4). A Dramatic budding in close vicinity obviously results in the formation of oligomeric and giant particles (asterisks). B Due to their rod-like shape, recombinant baculoviruses $(B)$ can be easily distinguished from the budding $\mathrm{p} 55$ core particles 


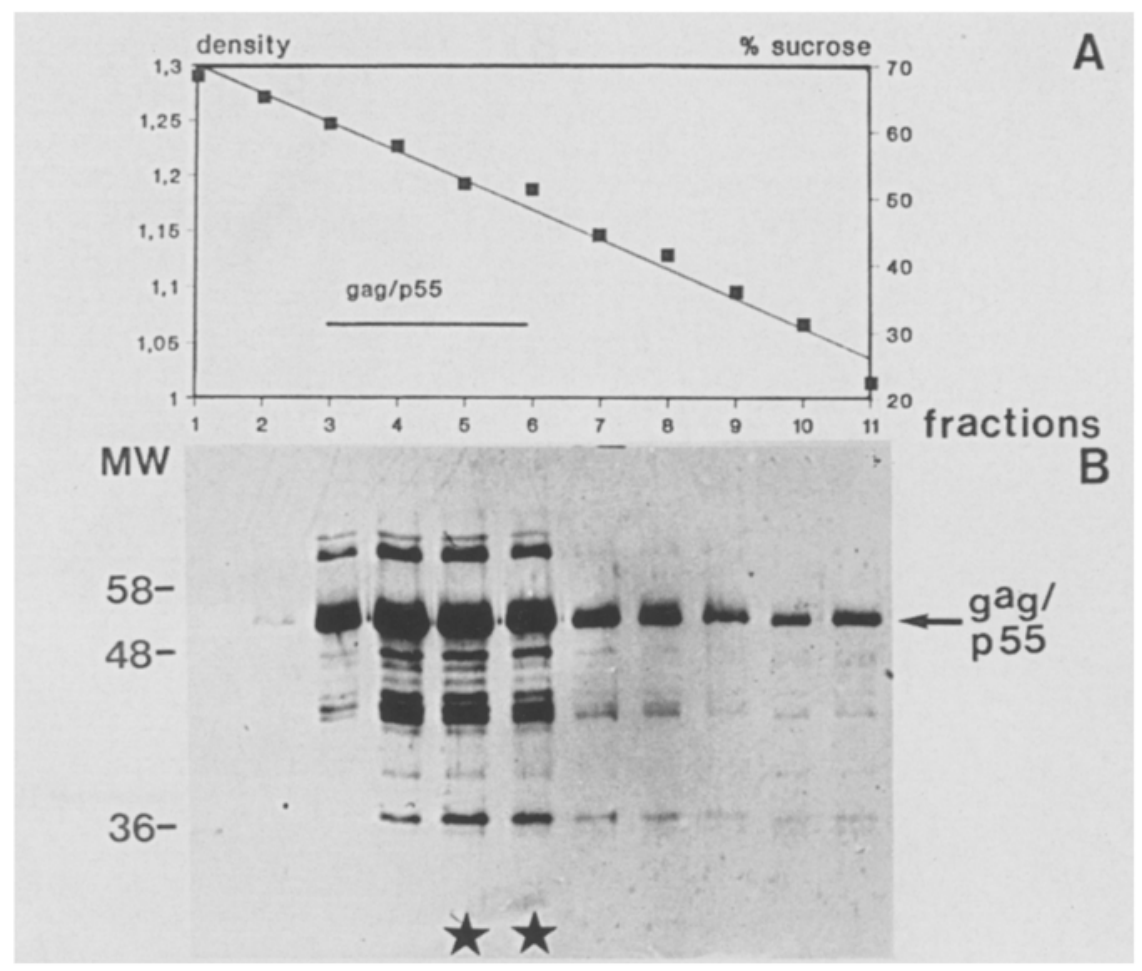

Fig. 7. Sucrose sedimentation analysis. Cells were infected with $10 \mathrm{pfu} / \mathrm{cell}$ b-p55. Supernatant was harvested 5 days p.i., precleared $(3000 \times \mathbf{g})$ in a Kontron centrifuge and layered onto a sucrose gradient (10-50\%). After $2 \mathrm{~h}$ of centrifugation in a TST 41.14 rotor, sequential fractions were analyzed by Western blot analysis using the $\mathrm{p} 24$ monoclonal antibody (B). $\mathbf{A}$ The density of the serial fractions is indicated ( $\boldsymbol{\square})$; antigenic peak fractions are labeled with a black bar. B Fractions containing particulate p 55 core structures are indicated $(\star)$

particles were obtained from supernatants harvested 5 days p.i. (Fig. 7). Specifically detected bands of a higher molecular weight might represent oligomerized p 55 precursor proteins. Signals of a reduced molecular weight might be due to a not specific degradation of the core precursor protein by cytoplasmic proteases randomly packaged into the core particles during the budding process. Negative staining and examination by electron microscope of the antigenic peak fractions demonstrated particulate core antigens at a sucrose density of 1.16$1.19 \mathrm{~kg} / \mathrm{l}$. Particulate structures were budding into the culture supernatant to an estimated concentration of $20-30 \mathrm{mg} / \mathrm{l}$. Peak fractions corresponded to a major $55 \mathrm{kDa}$ protein species which was specifically detected in Western blots by monoclonal antibodies to $\mathrm{p} 24$ (Fig. 7). In gradients performed with b-p55PR derived culture supernatants, this peak fraction, containing particulate structures was missing (data not shown). These data clearly confirmed that (i) p55 gag particles are budding from b-p 55 infected Sf 9 cells into the culture medium and that (ii) particle formation is considerably reduced by HIV-1 protease mediated processing as demonstrated in b-p55 PR infected Sf 9 cells. 


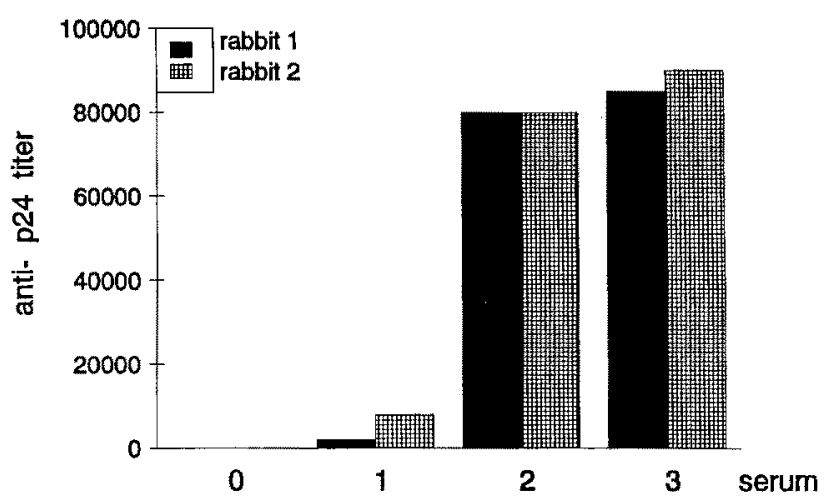

Fig. 8. $p 24$ specific IgG antibody response induced in $2 \mathrm{rab}$ bits. Sera were taken 10 days following the injection of purified p55 gag particles; 0 preimmune sera; $1-3$ antisera

\section{Immunogenicity of immature HIV virus-like particles}

To demonstrate the immunogenicity of HIV-1 virus like particles, supernatants of b-p55 infected Sf 9 cells were harvested and the immature particles were partially purified as described in Material and methods. Primary immunisation of two rabbits was performed using $67 \mu \mathrm{g}$ of HIV-core antigen in complete Freund's adjuvant, followed by two booster injections with the same antigen dose in incomplete Freund's adjuvant after 2 and 6 weeks. Ten days after each immunisation serum samples were tested for anti p $24 \mathrm{IgG}$ production by a commercial antigen specific ELISA (Behringwerke AG, Marburg, Federal Republic of Germany). Antibody titers following the primary and booster injections are shown in Fig. 8. The induced antibody titers were similar in both animals. The animals developed a strong anamnestic response following the first booster injection reaching titers in excess of $1 / 10^{5}$. A further booster injection did not markedly increase the response.

\section{Discussion}

Intrinsic adjuvant properties of particulate antigens are indicated by successful and routine application of recombinant $22 \mathrm{~nm}$ hepatitis B virus (HBV) surface antigen (HBsAG) particles as a protective vaccine in humans [40]. Particle formation was also reported for the production of HBV core antigen in E. coli and for the capsid precursors of several retroviruses and retrovirus-like particles expressed in eucaryotic expression systems $[1,7,17,18]$. Autologous and chimeric Ty-particles were producted in yeast cells and purified for the application in immunization experiments and clinical studies [27]. Vaccine mediated induction of an extensive humoral and cellular immune response to the HIV1 core proteins might prove important in HIV vaccine development. The HIV1 group specific antigen is highly conserved amongst different HIV-1 and HIV2 isolates and was characterized in the past as an important target of cell mediated [28, 42] and humoral immunity [30, 44]. We suggest that HIV-1 core particles themselves or products derived by adding additional sequence information are well suited as a safe and effective candidate vaccine. This study 
aimed at investigating the parameters (e.g., HIV protease mediated processing or amino-terminal myristylation of the gag precursor) involved in budding of HIV-1 core particles after expression of artificial gag-gene constructs in various expression systems. In order to optimize HIV-1 core particle formation, different procaryotic and eucaryotic expression systems were compared. For optimal conditions of comparison, identical basic constructs were used for the production of different $g a g$ derived recombinant proteins.

Core particle formation was not found in $E$. coli. One explanation could be the lack of posttranslational modifications which occur in authentic HIV infections $[8,41]$, but not in $E$. coli. As confirmed by our experiments analysing v-p55 and v-p55 $\mathrm{M}^{-}$infected SW 480 cells, glycine dependent $\mathrm{NH}_{2}$-terminal myristylation is essential for the budding of $100-160 \mathrm{~nm}$ immature $\mathrm{p} 55$ particles (Fig. 1). In contrast to the nuclear localization of unmyristylated $\mathrm{p} 55$ produced in the baculovirus system [6], we could not detected an accumulation of particulate structures in the nucleus of v-p55 M- infected SW 480 cells. Interestingly, amino-terminal myristylation of the gagpol precursor is not an absolute prerequisite for consecutive processing. This is shown by the processing of the core precursor in $\mathrm{v}-\mathrm{p} 55 \mathrm{M}^{-}$Pol infected $\mathrm{CV}-1$ cells thus underlining major differences in the capsid morphogenesis between lentiviruses and type D retroviruses [8] (Fig. 2A).

Comparing both of the tested eucaryotic expression systems with respect to their $\mathrm{p} 55$ particle forming capacity, we conclude that budding of immature gag particles is available from $\mathrm{v}-\mathrm{p} 55$ infected mammalian cells as well as from Sf 9 insect cells infected with a p 55 recombinant baculovirus. Detailed morphological analysis of p55 gag particles budding from infected SW 480 and Sf 9 cells by ultrathin section electron microscopy demonstrated a fine structure very similar to the immature gag particles detected in authentic HIV infections [5]. This proposes a common mechanism for assembly of immature particles at the cytoplasmic side of the plasma membrane (Figs. 4 and 6). However, we found dramatic differences in the amounts of budding of immature core particles between the expression systems tested. Corresponding to the fulminant expression of p 55 in b-p55 infected cells, we found cluster-like accumulations of gag molecules at the inner cell membrane. A cluster of membrane bound gag precursor molecules results in hotspots of budding particles (Fig. 6). Due to the abundant budding, a considerable part of the detected free particles produced from b-p55 infected insect cells is specified by oligomeric aggregates. In contrast, we find only small amounts of single, not oligomerized p 55 particles budding from the plasma membrane of v-p55 infected SW 480 cells, possibly due to the significantly weaker expression of the gag precursor in the vaccinia system. Based on densitometric analysis of immunoblots we found a 50 fold excess of gag-protein synthesis in the baculovirus system (b-p55) as compared to the production of the core precursor by recombinant vaccinia virus in mammalian cells (data not shown). According to the described existence of cellular myristyl moiety receptor molecules $[32,33]$, a reduced number of these receptors in the 
tested mammalian cells might be responsible for the comparably low yield of p55 gag particles in the vaccinia virus system. Moreover, differences in growth conditions between Sf 9 cells $\left(28^{\circ} \mathrm{C}\right)$ and SW 480 cells $\left(37^{\circ} \mathrm{C}\right)$ might influence the membrane fluidity and consequently the formation of $g a g$-particles.

Addition of PR- or pol-coding sequences to the gag gene did not provide for the synthesis of particles that resemble naturally occurring mature capsid structures including the typical conical p 24 core $[5,16]$. Interestingly, addition of the exact PR coding sequence to the gag gene in its original reading frame ( $\mathrm{v}-\mathrm{p} 55 \mathrm{PR}$ ) was not sufficient to induce significant processing of the core precursor in the vaccinia virus system (Fig. 2 A). This unexpected result is in agreement with findings of Shioda et al. [36]), but is in clear contrast to the observed complete processing of the gag-precursor in extracts of b-p55PR infected Sf 9 cells (Fig. 5). Addition of the entire pol coding sequence to the gag gene and expression by vaccinia viruses ( $\mathrm{v}-\mathrm{p} 55 \mathrm{Pol}, \mathrm{v}-\mathrm{p} 55 \mathrm{M}^{-} \mathrm{Pol}$ ) resulted in a significant, but not complete processing of the polyprotein precursors, that resembled the authentic situation in HIV-infected $\mathrm{H} 9$ cells. This strongly indicates the involvement of regions $\mathrm{COOH}$-terminal from the actual PR-domain in efficient formation of enzymatically active protease dimers (Fig. $2 \mathrm{~A}$ ). In contrast, complete processing of the gag precursor shown by b-p55PR infected Sf 9 cells (Fig. 5, lane 3) and by v-p55 PR-FS infected mammalian cells (Fig. 2 B) drastically reduced core particle formation (Fig. 1). We propose, that dimerization of monomeric PR-domains, suggested to be necessary for complete processing of precursor molecules, which is not found in HIV infected cells, requires high intracellular concentrations of the gag PR-readthrough proteins within the cell. Such concentrations possibly are only reached in artificial expression systems like, e.g., b-p55 PR infected Sf 9 cells or in CV-1 cells infected with the v-p55 PRFS vaccinia virus.

However, even partial processing did not finish the core maturation process. As demonstrated in a number of ultrathin sections, we could only find core particles budding from the plasma membrane described as immature virus particles by Gelderblom et al. [5]. These results clearly indicate, that the synthesis of mature capsids in artificial expression systems can not be achieved by simple addition of the protease or polymerase gene to the gag open reading frame. Recent publications described the synthesis of gag particles containing an electron dense core and HIV-RNA using a vaccinia driven expression system [11] and in stable transfection experiments [12]. A common feature of both experiments is the use of DNA constructs including, in addition to the PR coding sequence, an RNA packaging signal, located only few basepairs upstream of the p 55 coding sequence [22]. In contrast, using gag sequences lacking the packaging signal sequence, we could not find RNA packaged in our gag particle preparations in Nothern blot analysis (data not shown). Taken together, these observations suggest, that viral HIV RNA containing the packaging signal is at least partially involved in the capsid maturation process.

Immunological evaluation of immature gag particles purified from b-p55 
infected Sf 9 cells showed a high immunogenicity in rabbits. Preliminary results, using p 55 recombinant vaccinia viruses (v-p55) for immunisation of rabbits gave significantly lower titers of specific antibodies suggesting that recombinant core particles were more immunogenic than the vaccinia constructs (unpubl. data). Taken together, we conclude that empty immature p55gag particles lacking viral RNA and produced by recombinant baculovirus are well suited as a noninfectious vaccine component. Parallel studies try to identify regions in the gag precursor that can be exchanged by immunologically relevant epitopes encoded by other HIV-1 genes without disturbing the p 55 particle forming capacity. This approach aimed at extending the immunological spectrum of the p55 gag derived particles by inserting cytotoxic and helper T-cell determinants as well as neutralizing epitopes such as the gp 120 principal neutralizing determinant V 3 (PND). Adverse side effects such as gp 120 dependent, antibody mediated enhancement of infection or the induction of immune suppresive effects would be excluded. The safety of engineered particulate vaccines would be guaranteed by the lack of viral LTR elements and primer binding sites. Moreover, deletion of the RNA packaging signal, the lack of enzymes (PR, RT, IN) and essential regulatory proteins (Tat, Rev, Vif) important for a possible recombination to infectious particles would enhance the safety of such a candidate vaccine.

\section{Acknowledgements}

For the initial studies, Dr. Gelderblom's spontaneous support was of great help for this project. This work was supported by the FVP-BGA $1-88$.

\section{References}

1. Beesley KM, Francis MJ, Clarke BE, Beesley IE, Dopping-Heppenstal PJ, Clare JJ, Brown F, Romanos MA (1990) Expression in yeast of aminoterminal peptide fusions to hepatitis B core protein antigen and their immunological properties. Biotechnology 8: $644-649$

2. Debouck C, Gorniak JG, Stricker JE, Meek TD, Metcalf BW, Rosenberg M (1987) Human immunodeficiency virus protease expressed in Escherichia coli exhibits autoprocessing and specific maturation of the gag precursor. Proc Natl Acad Sci USA 84: 8903-8906

3. Delchambre M, Gheysen D, Thines D, Thiriart C, Jacobs E, Verdin E, Horth M, Burny A, Bex F (1989) The gag precursor of simian immunodeficiency virus assembles into virus-like particles. EMBO J 8: 2653-2660

4. Flexner C, Broyles SS, Earl P, Chakrabarti S, Moss B (1988) Characterization of human immunodeficiency virus gag/pol gene products expressed by recombinant vaccinia viruses. Virology 166: 339-349

5. Gelderblom HR, Ozel M, Pauli G (1989) Morphogenesis and morphology of HIV. Structure-function relations. Arch Virol 106: 1-13

6. Gheysen D, Jacobs E, de Foresta F, Thiriart C, Francotte M, Thines D, de Wilde M (1989) Assembly and release of HIV-1 precursor $\operatorname{Pr} 55$ gag virus like particles from recombinant baculovirus infected cells. Cell 59: 103-112

7. Gilmour JE, Senior JM, Burns NR (1989) A novel method for the purification of HIV- 
$1 \mathrm{p} 24$ protein from hybrid Ty virus-like particles (TY-VPL's). J Aqu Immunodef Synd 3: $717-723$

8. Göttlinger HE, Sodroski JG, Haseltine WA (1989) Role of the capsid precursor processing and miristylation in morphogenesis and infectivity of human immunodeficiency virus type 1. Proc Natl Acad Sci USA 86: 5781-5785

9. Gowda SD, Stein BS, Engelman EG (1989) Identification of protein intermediates in the processing of the p $55 \mathrm{HIV}-1$ gag precursor in cells infected with recombinant vaccinia virus. J Biol Chem 264: 8459-8462

10. Gregersen JE, Wege H, Preiss L, Jenatsch KD (1988) Detection of human immunodeficiency virus and other retroviruses in cell culture supernatants by a reverse transcriptase microassay. J Virol Methods 19: 161-168

11. Haffar O, Garrigues J, Travis B, Moran P, Zarling J, Hu SL (1990) Human immunodeficiency virus-like, nonreplicating particles assemble in a recombinant vaccinia virus expression system. J Virol 64: 2653-2659

12. Haynes JR, Cao SX, Rovinski B, Sia C, James O, Dekaban GA, Klein MH (1991) Production of immunogenic HIV-1 viruslike particles in stably engineered monkey cell lines. AIDS Res Human Retroviruses 7: 17-27

13. Henderson LE, Krutzsch HC, Oroszlan S (1983) Myristyl amino-terminal acylation of murine retrovirus proteins: an unusual post-transcriptional protein modification. Proc Natl Acad Sci USA 80: 339-343

14. Jacks T, Madhani HD, Masiarz FR, Varmus HE (1988) Signals for ribosomal frameshifting in Rous sarcoma virus gag-pol region. Cell 55: 447-458

15. Kaplan LM, Mardon G, Bishop JM, Varmus HE (1988) The first seven amino acids encoded by $\mathrm{v}$-src oncogene act as a myristylation signal; lysine 7 is a critical determinant. Mol Cell Biol 8: 2435-2441

16. Katsumoto L, Hattori N, Kurimura $T$ (1987) Maturation of human immunodeficiency virus, strain LAV, in vitro. Intervirology $27 ; 148-153$

17. Kingsman SM, Kingsman AJ (1989) Host vector systems. Philos Trans R Soc Lond [Biol] 324: 477-485

18. Kingsman SM, Adams SE, Kingsman AJ (1989) The yeast retrotransposon Ty: molecular genetics and exploitation. Biotechnology 13: 145-163

19. Kramer RA, Schaber MD, Skalka AD, Ganguly K, Wong Staal F, Reddy EP (1986) HTLV-III gag protein is processed in yeast by the virus pol protease. Science 231: $1580-1584$

20. Kräuslich HG, Schneider H, Zybarth G, Carter CA, Wimmer E (1988) Processing of in vitro synthesized gag precursor proteins of human immunodeficiency virus (HIV) type 1 by HIV proteinase generated in Escherichia coli. J Virol 62: 4393-4397

21. Laemmli $U$ (1970) Cleavage of structural proteins during the assembly of the head of bacteriophage $T$ 4. Nature 227: 680-685

22. Lever A, Göttlinger H, Haseltine W, Sodroski J (1989) Identification of a sequence required for efficient packaging of human immunodeficiency virus type 1 RNA into virions. J Virol 63: 4085-4087

23. Lillehoj EP, Salazar FH, Mervis RJ, Raum MG, Chan HW, Ahmad N, Venkatesan $S$ (1988) Purification and structural characterization of the putative gag-pol protease of human immunodeficiency virus. J Virol 62: 3053-3058

24. Mackett MG, Smith L, Moss B (1984) General method for production and selection of infectious vaccinia virus recombinants expressing recombinant foreign genes. J Virol 49: $857-864$

25. Mervis RJ, Ahmad N, Lillehoj EP, Raum MG, Salazar FH, Chan HW, Venkatesan $S$ (1988) The gag gene products of human immunodeficiency virus type 1: alignment within the gag open reading frame, identification of posttranslational modifications and evidence for alternative gag precursors. J Virol 62: 3993-4002 
26. Michel ML, Mancini M, Riviere Y, Dormont D, Tiollais P (1990) T- and B-lymphozyte responses to human immunodeficiency virus (HIV) type 1 in macaques with hybrid HIV/hepatitis B surface antigen particles. J Virol 64: 2452-2455

27. Mills KH, Kitchin PA, Mahon BP, Barnard AL, Adams SE, Kingsman SM (1990) HIV p 24-specific helper T-cell clones from immunized primates recognize highly conserved regions of HIV-1. J Immunol 144: 1677-1683

28. Nixon DF, Townsand AR, Elvin JG, Rizza CR, Gallway J, McMichael AJ (1988) HIV-1 gag specific cytotoxic T-lymphocytes defined with recombinant vaccinia virus and synthetic peptides. Nature 336: 484-487

29. Overton HA, Fuji Y, Price IR, Jones IM (1989) The protease and gag gene products of the human immunodeficiency virus: authentic cleavage and post-translational modification in an insect cell expression system. Virology 170: 107-116

30. Papsidero LD, Sheu M, Ruscetti FW (1989) Human immunodeficiency virus type 1neutralizing monoclonal antibodies which react with $\mathrm{p} 17$ core protein: characterization and epitope mapping. J Virol 63: 267-272

31. Ratner L, Haseltine W, Patarca R (1985) Complete nucleotide sequence of the AIDS virus, HTLV III. Nature 313: 227-284

32. Rein A, McClure MR, Rice NR, Luftig RB, Schultz AM (1986) Myristylation site in $\operatorname{Pr} 65$ gag is essential for virus particle foramtion by Moloney murine leucemia virus. Proc Natl Acad Sci USA 83: 7246-7250

33. Rhee SS, Hunter E (1987) Myristylation is required for intracellular transport but not for assembly of D-type retrovirus capsids. J Virol 61: 1045-1053

34. Sambrook I, Fritsch EF, Maniatis T (1989) Molecular cloning; a laboratory manual. Cold Spring Harbor Laboratory, New York

35. Schultz AM, Oroszlan S (1983) In vivo modification of retroviral gag gene-encoded polyproteins bymyristic acid. J Virol 46: $355-361$

36. Shioda T, Shibuta H (1990) Production of human immunodeficiency virus (HIV)-like particles from cells infected with recombinant vaccinia viruses carrying the gag gene of HIV. Virology 175: 139-148

37. Smith AJ, Cho MI, Hammarskjold ML, Rekosh D (1990) Human immunodeficiency virus type 1 Pr 55 gag and $\operatorname{Pr} 150$ gagpol expressed from a simian virus 40 late replacement vector are efficiently processed and assembled into virus like particles. $\mathbf{J}$ Virol 64: $2743-2750$

38. Smith GE, Ericson BL, Moschera J, Lahm HW, Chizzonite R, Summers MD (1985) Modification and secretion of human interleukin 2 produced in insect cells by a baculovirus expression vector. Proc Natl Acad Sci USA 82: 8404-8408

39. v Brunn A (1989) Das Oberflächenantigen des Hepatitis B Virus als Trägersystem von Epitopen eines merozoiten Oberflächenmoleküls des Malariaerregers Plasmodium Falciparum - eine neue Möglichkeit der Impfstoffentwicklung? PhD Thesis, University of Munich, Munich, Federal Republic of Germany

30. Valenzuela P, Medina A, Rutter WJ, Ammerer G, Hall BD (1982) Synthesis and assembly of hepatitis B virus surface antigen particles in yeast. Nature 298: 347-350

41. Veronese FD, Copeland TD, Oroszlan S, Gallo RC, Sarngadharan MG (1988) Biochemical and immunological analysis of human immunodeficiency virus gag gene products $\mathrm{p} 17$ and $\mathrm{p} 24$. J Virol 62: 795-801

42. Walker BD, Chakrabarti S, Moss B (1987) HIV specific cytotoxic T-lymphocytes in seropositive individuals. Nature 328: $345-348$

43. Wilcox C, Hu JS, Olson EN (1987) Acylation of proteins with myristic acid occurs cotranslationally. Science 238: 1275-1278

44. Wolf H, Modrow S, Soutschek E, Motz M, Grunow R, Döbl H, v Baehr R (1990) Herstellung, Kartierung und biologische Charakterisierung von monoklonalen Antikörpern gegen das core protein $(\mathrm{p} 24)$ des humanen Immundefizienz-Virus. AIFO 1: 24-29 
Authors' address: H. Wolf, Institut für Medizinische Mikrobiologie und Hygiene, Universität Regensburg, Franz-Josef-Strauß-Allee 11, D-W-8400 Regensburg, Federal Republic of Germany.

Received December 30, 1991 